\title{
The Geology and Paleontology of Tule Springs Fossil Beds National Monument, Nevada
}

On December 19, 2014, Tule Springs Fossil Beds National Monument in Nevada was established by Congress as the 405th unit of the National Park Service to "conserve, protect, interpret, and enhance for the benefit of present and future generations the unique and nationally important paleontological, scientific, educational, and recreational resources and values of the land" (P.L. 113-291, sec. 3092).

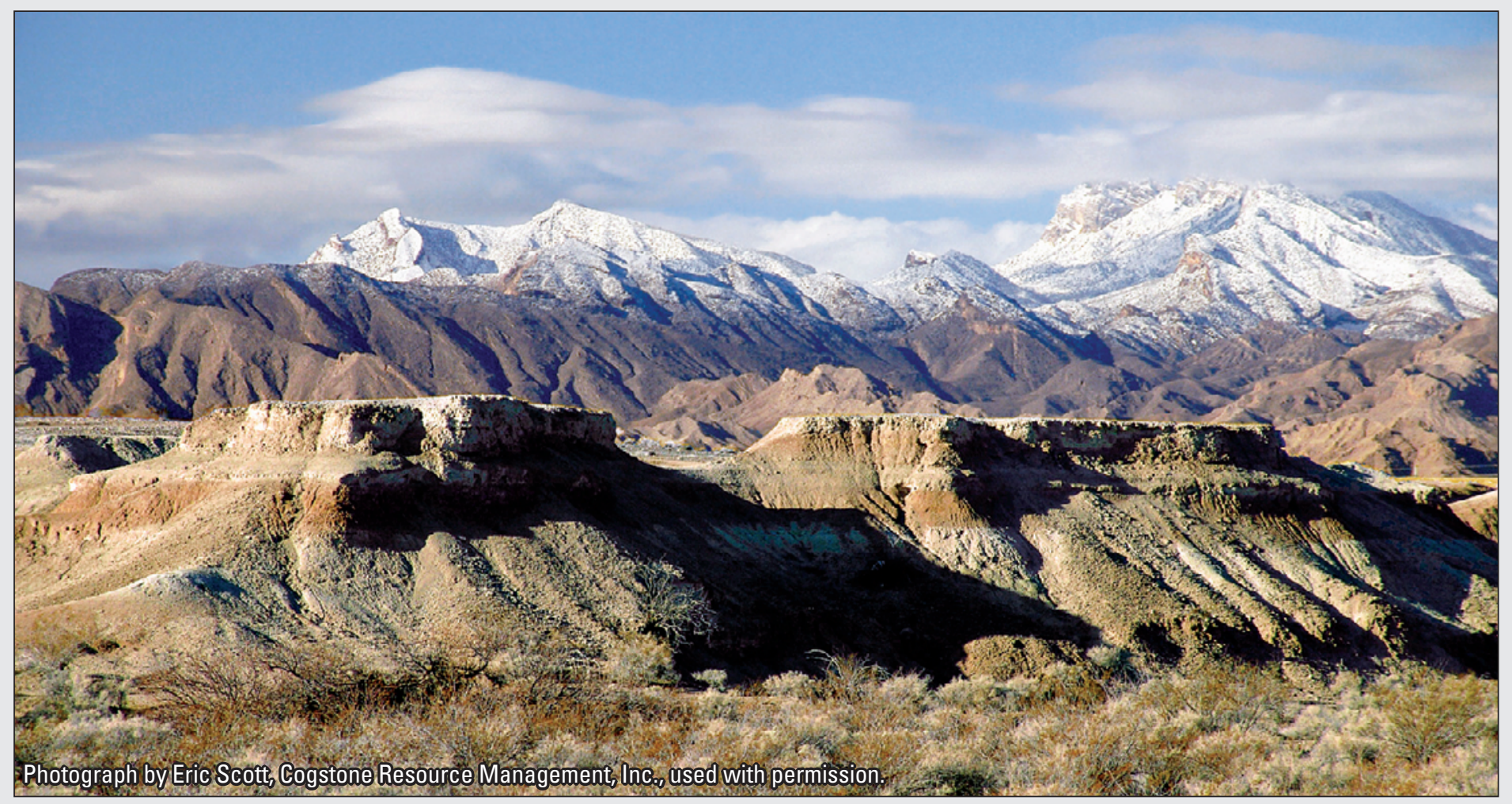

The upper Las Vegas Wash cuts through sediments formed by ancient springs and marshes that blanketed the Las Vegas Valley floor during the Pleistocene Epoch. These deposits have yielded thousands of vertebrate fossils and contain valuable information on past climatic and environmental conditions. This is Tule Springs Fossil Beds National Monument.

\section{A Brief History of Tule Springs}

Vertebrate fossils have been known from the Las Vegas Valley for more than a century, beginning in 1903 when Josiah Spurr of the U.S. Geological Survey reported teeth and bones in the sediments exposed in the wash between Corn Creek Springs and Tule Springs (Spurr, 1903). Several scientific investigations followed, including the extensive and multidisciplinary Tule Springs Expedition of 1962-63 that sought to determine if humans and Pleistocene megafauna coexisted in the area. In what came to be known as the Big Dig, the Tule Springs Expedition combined traditional field techniques with massive earth-moving activities. Heavy construction equipment carved enormous trenches into the sediments at Tule Springs to expose vertical walls as deep as 13 meters (nearly 43 feet!), which allowed the sediments to be studied in detail. Geologist C. Vance Haynes, Jr., directed the geological investigations and subdivided the fossil-rich sediments into distinct units of the Las Vegas Formation. He also assigned ages to the units using the newly developed radiocarbon dating technique. Haynes' targeted approach demonstrated that human-made artifacts only occurred in the youngest levels of the formation - those layers lacking the fossilized remains of Pleistocene animals (Haynes, 1967). Consequently, the hypothesis that early humans coexisted with Pleistocene megafauna at Tule Springs was disproven, and interest in the site faded. A long intermission in scientific research followed, lasting until the 2000s when museum scientists conducted comprehensive and systematic paleontological excavations of the area. The scientists discovered nearly 600 new fossil localities and collected and curated more than 40,000 vertebrate fossils. Work in Tule Springs Fossil Beds National Monument continues today through the efforts of scientists from the U.S. Geological Survey, National Park Service, and academic institutions across the country. 


\section{A Story of Water}

Tule Springs Fossil Beds National Monument preserves nearly 23,000 acres of the fossil-rich Las Vegas Formation. The formation's silty, light-colored sediments were once thought to be the remnants of a large Pleistocene lake, but it is now known that they actually represent a vast spring ecosystem that existed throughout the Las Vegas Valley for millennia (Quade, 1986). During the Pleistocene, the climate was wetter than today, and the water table was so high that groundwater flowed up to the ground surface. The soggy ground and dense vegetation trapped dust and sand transported by water and wind, which mixed with organic material and chemical precipitates to form wetland deposits. Specific spring environments, such as marshes and wet meadows, spring pools and ponds, and spring-fed streams, can be recognized through careful examination of the deposits. These environments are comparable to modern spring ecosystems and help reconstruct past environmental and hydrologic conditions in the valley.

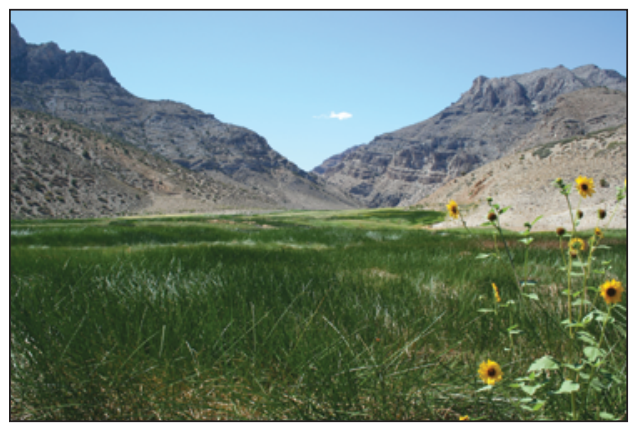

Marshes/wet meadows

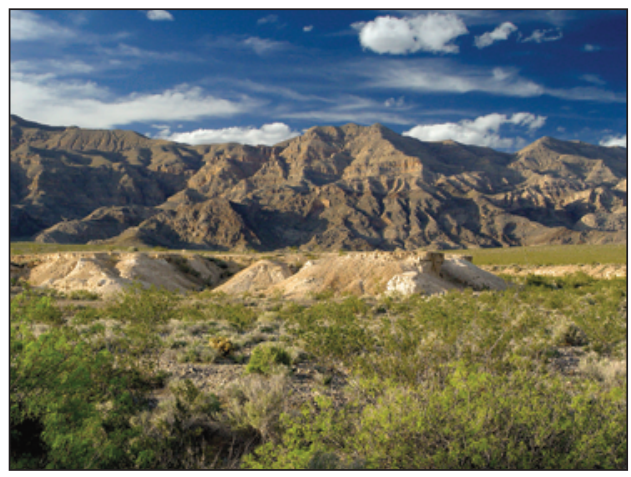

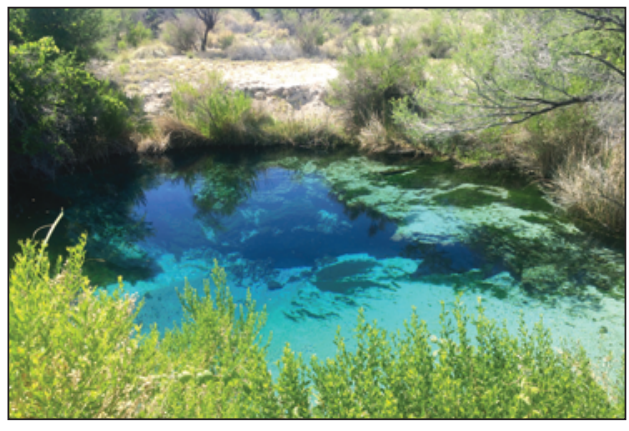

Spring pools/ponds

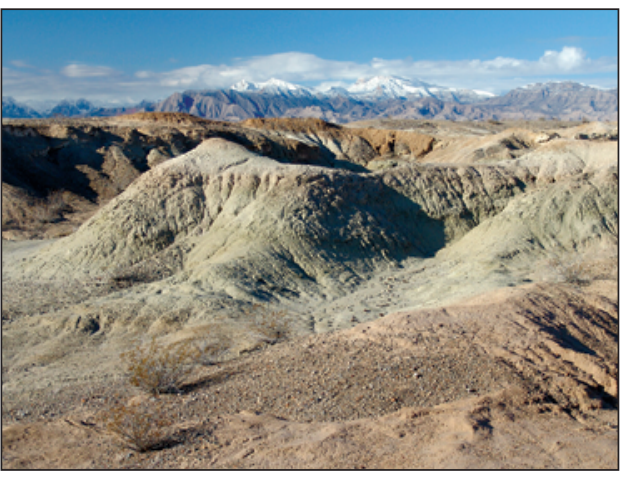

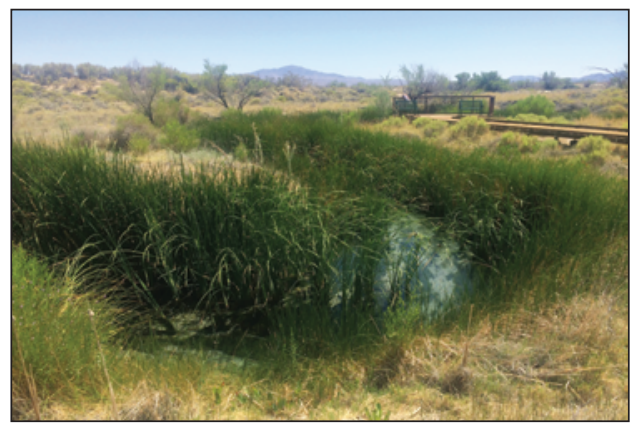

\section{Spring-fed streams}

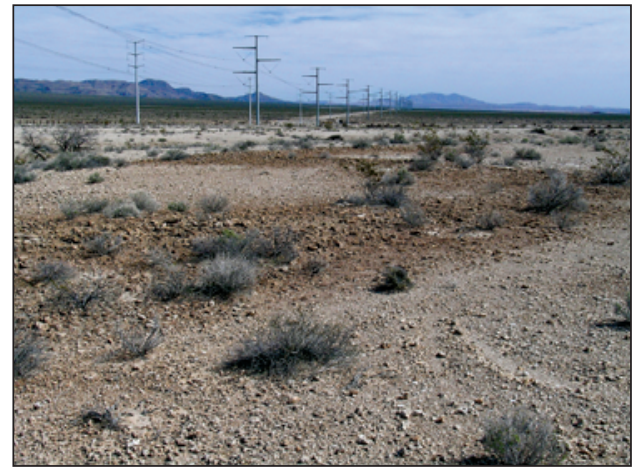

Examples of spring environments in present-day wetlands (upper panels) and their counterparts from the geologic past (lower panels). The types of springs and their distribution throughout the upper Las Vegas Wash are directly related to the location of buried faults, the complexity of local and regional aquifers, and the height of the water table both today and in the past. The two lower left photographs by Eric Scott, Cogstone Resource Management, Inc., used with permission.

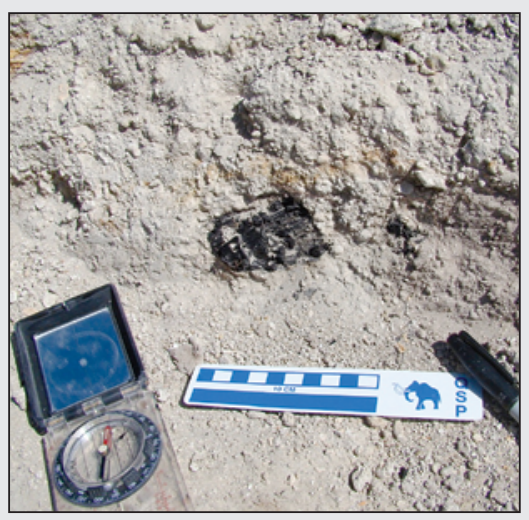

\section{Timing is everything...}

The Las Vegas Formation consists of 17 different geologic units that collectively span more than 500,000 years (Springer and others, 2018). Each unit dates to a specific period of geologic time and exhibits a unique set of physical characteristics that can be used to distinguish one from another. This is important because ages of the units can be used to date vertebrate fossils that are found within them. Radiocarbon dating saw its first widespread use during the Tule Springs Expedition in the early 1960s. Never before had a fossil site been dated in this way. Scientists have continued to refine the chronology of the deposits by radiocarbon dating charcoal (left), which determines when plants found in the sediment were last alive, and luminescence dating (right), which determines when the sediments were last exposed to light or heat.

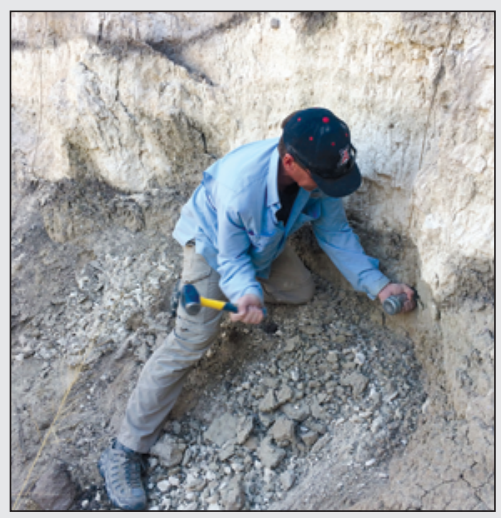




\section{A Story of Life}

The vertebrate fossil assemblage found in Tule Springs Fossil Beds National Monument, called the Tule Springs local fauna, represents one of the most important Pleistocene vertebrate faunas in the American Southwest. The fauna occurs throughout most of the Las Vegas Formation and spans from approximately 100,000 years ago to 12,500 years ago (Scott and others, 2017). The Tule Springs local fauna is both abundant and diverse and includes numerous species of large mammals, as well as smaller animals such as frogs, lizards, snakes, birds, and rodents. Invertebrates such as aquatic and terrestrial snails, tiny clams, and ostracodes are also common. All of the fossils and geologic deposits in the monument are protected for posterity. Ongoing and future scientific studies should continue to reveal a wealth of information about the ever-changing ecosystems in the Las Vegas Valley and the plants and animals that once called it home.

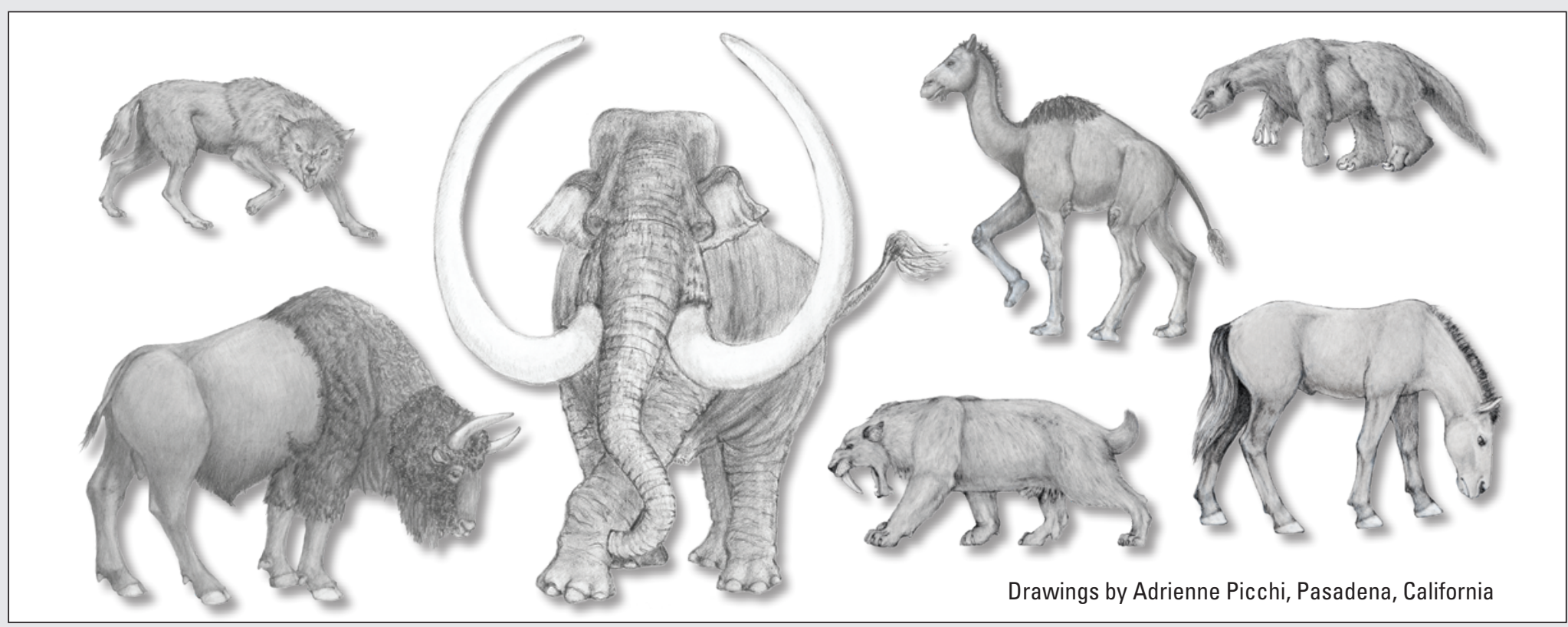

The Columbian mammoth (Mammuthus columbi) is the iconic animal of Tule Springs Fossil Beds National Monument. Mammoth remains have been discovered throughout the monument and dominate the Tule Springs local fauna in terms of sheer numbers of fossils. Yesterday's camel (Camelops hesternus) was widespread in western North America during the late Pleistocene and is the second most common animal found at Tule Springs. Two species of bison were also present in the valley, a long-horned species (Bison latifrons) and a smaller species (Bison antiquus). A large stout-legged horse (Equus scotti), a small stout-legged horse (Equus sp.), and a small stilt-legged species (Haringtonhippus francisci) also lived there during the late Pleistocene, as did Jefferson's ground sloth (Megalonyx jeffersonii) and Shasta ground sloth (Nothrotheriops shastensis). In addition, rare fossils of American lion (Panthera atrox), and new findings of dire wolf (Canis dirus) and saber-toothed cat (Smilodon fatalis), show that carnivores prowled the valley (Scott and Springer, 2016). All of these majestic animals went extinct as the Pleistocene Epoch came to a close.

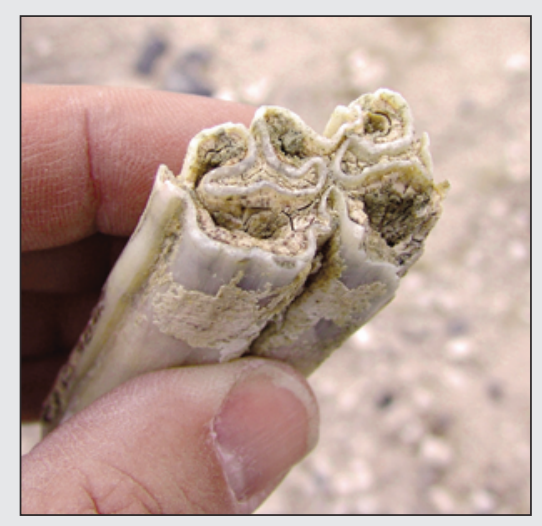

\section{... and context is critical!}

The thousands of Pleistocene fossils from Tule Springs Fossil Beds National Monument are spectacular, but it is their geological context that makes them truly special. The geologic framework of fossil sites in the monument allows scientists to assess the age of the fossils, determine what the environment was like when the animals were alive, evaluate how extinct species lived and died, measure how populations changed over time, and understand how the animals adapted to the challenges of life under a changing climate.

Left: Fossil horse tooth from Tule Springs. Right: U.S. Geological Survey research geologist Kathleen Springer examining a sequence of wetland deposits in the upper Las Vegas Wash. Photograph by Eric Scott, Cogstone Resource Management, Inc., used with permission.

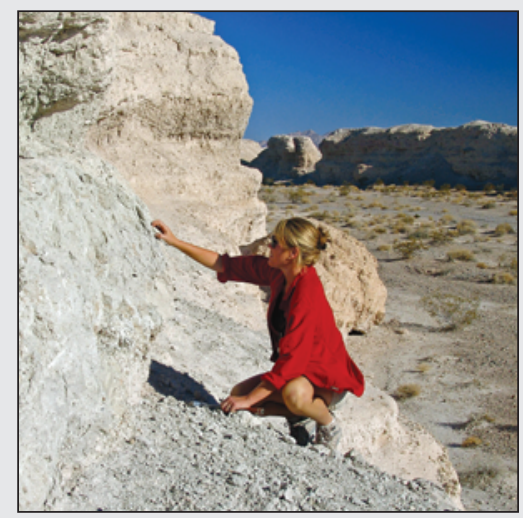




\section{U.S. Geological Survey Science in the Park}

\section{Ice Age Climate}

The Pleistocene Epoch began about 2.6 million years ago and ended 11,700 years ago. During this period of time, Earth's climate saw numerous swings from cold to warm and back again. Massive continental ice sheets, extensive alpine glaciers, numerous large lakes, and expansive spring-fed wetlands characterized the cold periods, called glacials. During the warm periods, or interglacials, the ice sheets retreated and the deserts dried. These glacial-to-interglacial cycles were long, lasting tens to hundreds of thousands of years. During both glacial and

\section{Megafauna Extinctions}

Mammoths, sloths, camels (jaw shown at right), horses, and dozens of other large animals disappeared from North America at the end of the Pleistocene. The question of what caused this extinction has never been fully answered. Hypotheses that seek to explain the demise of the Pleistocene megafauna include climate change, increased competition for resources, overhunting by humans,

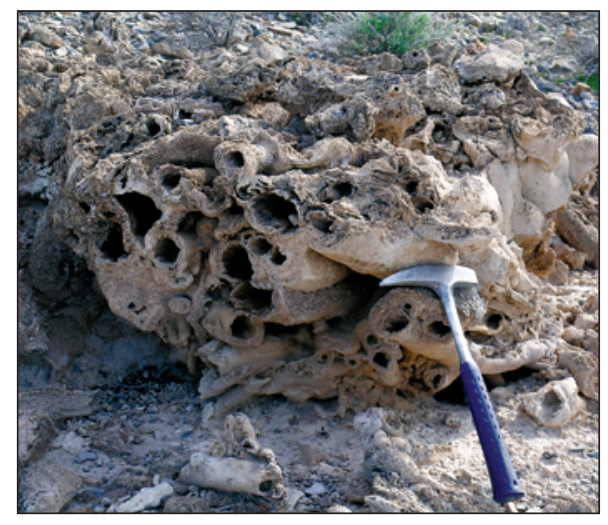

\section{References}

Haynes, C.V., Jr., 1967, Quaternary geology of the Tule Springs Area, Clark County, Nevada, in Wormington, H.M., and Ellis, D., eds., Pleistocene studies in southern Nevada: [Carson City] Nevada State Museum Anthropological Papers no. 13 , p. 15-104.

Quade, J., 1986, Late Quaternary environmental changes in the upper Las Vegas Valley, Nevada: Quaternary Research, v. 26, p. 340-357.

Scott, E., and Springer, K.B., 2016, First records of Canis dirus and Smilodon fatalis from the late Pleistocene Tule Springs local fauna, upper Las Vegas Wash, Nevada: PeerJ, v. 4, e2151, 17 p.

Scott, E., Springer, K.B., and Sagebiel, J.C., 2017, The Tule Springs local fauna-Rancholabrean interglacial times, numerous rapid climate fluctuations operating over decades to centuries also affected the availability of water on the landscape.

Although glaciers were not present in the Las Vegas Valley during the Pleistocene, water was in abundance, and wetlands blanketed much of the valley floor. These ecosystems were extremely sensitive to changes in climate. Multiple cycles of erosion, deposition, and soil formation occurred as the wetlands expanded and contracted in sync with abrupt global cooling and warming events before largely disappearing as the

widespread disease, and even an extraterrestrial impact event. The deposits in the upper Las Vegas Wash may offer important clues that could help solve this mystery. Scientists are using the Tule Springs fossils to track the abundance of mammals as the Pleistocene came to a close, allowing them to relate changes in populations to climate fluctuations and the arrival of humans to assess how the extinctions may have unfolded.

\section{Carbonate Rivers}

About 10,600 years ago, a network of spring-fed streams meandered across the Tule Springs area. The stream channels became frozen in time in the form of tufa. Tufa is calcium carbonate that precipitates from cool, spring-fed waters. This variety of tufa forms in the presence of algae and water-loving plants, coating leaves, twigs, branches, last glacial period came to a close (Springer and others, 2015).

Geologic deposits in the valley also show evidence of megadroughts, which typically lasted for a few centuries. These events severely impacted flora and fauna that depended on the springs and wetlands for water. Scientists continue to investigate the geologic, chronologic, and hydrologic context of vertebrate fossil localities in Tule Springs Fossil Beds National Monument to determine how the animals, and early human inhabitants, survived times of rapid climate change in the recent geologic past.

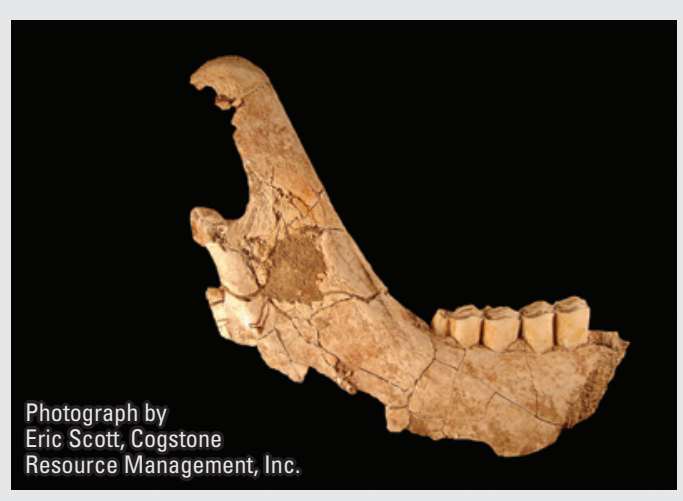

and logs. At first, it is soft and spongy, but when the springs dry up, it hardens into the rocky form that is seen today throughout the park. Tule Springs is home to the only braided fluvial tufa system in North America, preserving a network of stream channels just as they appeared on the landscape thousands of years ago. (Left, spectacular tufa from an ancient stream channel)

By Kathleen B. Springer and Jeffrey S. Pigati of the U.S. Geological Survey and Eric Scott of Cogstone Resource Management, Inc.

vertebrates from the Las Vegas Formation, Nevada: Quaternary International, v. 443A, p. 105-121.

Springer, K.B., Manker, C.R., and Pigati, J.S., 2015, Dynamic response of desert wetlands to abrupt climate change: Proceedings of the National Academy of Sciences of the United States of America, v. 112, no. 47, p. 14522-14526.

Springer, K.B., Pigati, J.S., Manker, C.R., and Mahan, S.A., 2018, The Las Vegas Formation: U.S. Geological Survey Professional Paper 1839, 62 p. [Also available at https://doi.org/10.3133/pp1839.]

Spurr, J.E., 1903, Descriptive geology of Nevada south of the fortieth parallel and adjacent portions of California: U.S. Geological Survey Bulletin 208, 229 p.

\section{Acknowledgments}

We extend our appreciation to the National Park Service and the leadership of Tule Springs Fossil Beds National Monument for their support of our ongoing work there.

\section{For More Information}

U.S. Geological Survey,

Geosciences and Environmental Change Science Center,

https://www.usgs.gov/centers/gecsc

National Park Service,

Tule Springs Fossil Beds National Monument, https://www.nps.gov/tusk/

A contribution of the Paleohydrology of Desert Wetlands project, https://www.usgs.gov/desertwetlands 